\title{
Localized Amyloidosis of the Head and Neck
}

\author{
Iş1l Adadan Güvenç \\ Başkent University, İzmir
}

Turkey

\section{Introduction}

Amyloidosis is a benign, slowly progressive condition characterized by the presence of extracellular fibrillar proteins in a variety of organs and tissues. It can be categorized as systemic or localized. Head and neck involvement can be seen in both systemic and localized amyloidosis. Systemic amyloidosis results in involvement of many organs, and shortens life expectancy, whereas localized amyloidosis is usually benign (Yiotakis et al., 2009). In this extensive review, the presentation, diagnosis and treatment modalities of localized amyloidosis of the head and neck will be discussed.

\section{Localized amyloidosis of the head and neck}

Virchow, in 1851, was the first to use the term amyloid because of its starchlike reaction when treated with iodine and sulfuric acid. In 1842, however, Von Rokitansky was the first to identify this material in the liver and spleen. Symmers classified amyloidosis clinically as: primary amyloid (localized or general); secondary amyloid (localized or general); amyloid associated with multiple myeloma; and hereditary or familial amyloid. In systemic or generalized disease, amyloid is deposited in many organ systems and life expectancy is shortened (Kennedy \& Patel, 2000). The mean survival of patients with systemic forms is between 5 to 15 months, whereas those with localized forms have an excellent prognosis (Fahrner et al., 2004). Approximately 9\% of amyloidosis cases are localized (Kyle \& Bayrd, 1975). In localized amyloidosis of the head and neck, deposition of amyloid may be observed in individual organs without any systemic involvement. The progressive accumulation of amyloid deposits interferes with the normal structure of affected tissues resulting eventually in impairment of their function (Yiotakis et al., 2009). Life expectancy is not affected unless an enlarging laryngotracheal lesion goes unattended (Kennedy \& Patel, 2000).

Clinically, amyloidosis is divided into two main categories, systemic and localized. Types of systemic amyloidosis are AL, AA, familial and senile amyloidosis.

AL amyloidosis, formerly called, primary amyloidosis is seen in progressive systemic disease, plasma cell dyscrasia/multiple myeloma, and most localized forms of amyloidosis. AL amyloid associated with plasma cell dyscrasia is the most common form of amyloidosis, accounting for $75 \%$ of cases in the United States (Penner \& Muller, 2006).

AA amyloidosis, formerly called, secondary amyloidosis occurs in association with chronic inflammatory disorders, chronic infections, and accounts for only $5 \%$ of all amyloid cases. The amyloid fibril protein is derived from the circulating acute phase protein known as 
serum amyloid A (Panda et al., 2007). AA amyloidosis shows a predilection for the spleen, liver, kidney, lymph nodes, and adrenals, although no organ system is spared. AA amyloidosis may also occur in association with Hodgkin disease, genitourinary or gastrointestinal malignancies (Penner \& Muller, 2006). In systemic amyloidosis, proteinuria with nephrotic syndrome is often the first symptom; other manifestations include peripheral neuropathies, dementia and cognitive dysfunction, and organ enlargement, especially of the liver, kidney, spleen and heart (Sipe \& Cohen, 1998). Macroglossia is most frequently noted in the head and neck region. Other nonspecific signs and symptoms such as fatigue, weight loss, orthostatic hypotension, diarrhea, skeletal muscle pseudohypertrophy, skin papules or plaques, arrhythmias, renal failure, congestive heart failure and carpal tunnel syndrome can be seen. Renal failure is the major cause of death in systemic amyloidosis. Sudden death secondary to cardiac arrythmias is also common (Nandapalan et al., 1998). The median survival reported by Kyle and Greipp in 229 cases of systemic amyloidosis was 13 months for patients with amyloidosis only, and 5 months for those with amyloidosis and myeloma (Kyle \& Greipp, 1983).

\begin{tabular}{|c|c|c|}
\hline $\begin{array}{l}\text { Amyloid } \\
\text { Protein }\end{array}$ & Protein Precursor & Clinical Syndrome \\
\hline \multirow[t]{3}{*}{ AA } & apoSAA & Reactive (secondary) \\
\hline & & Familial Mediterranean fever \\
\hline & & Muckle-Wells syndrome \\
\hline \multirow[t]{3}{*}{ AL } & $\operatorname{Ig} \lambda, \operatorname{IgK}$ & Idiopathic (primary) \\
\hline & & Multiple myeloma \\
\hline & & Local nodular \\
\hline $\mathrm{AH}$ & ү1 heavy chain & Macroglobulinemia \\
\hline $\mathrm{A} \beta_{2} \mathrm{M}$ & $\beta_{2}$ microglobulin & Chronic hemodialysis arthropathy \\
\hline \multirow[t]{3}{*}{$A \beta$} & $\beta$-protein precursor & Alzheimer's disease \\
\hline & & Down's syndrome \\
\hline & & Hereditary cerebral angiopathy with bleeding \\
\hline \multirow[t]{3}{*}{$\mathrm{APrP}$} & Prion protein & Creutzfeldt-Jacob disease \\
\hline & & Gerstmann-Straussler syndrome \\
\hline & & Kuru \\
\hline \multirow[t]{2}{*}{ AIAPP } & Amyloid insulin & Diabetes mellitus type 2 \\
\hline & polypeptide & Insulinoma \\
\hline AANF & $\begin{array}{l}\text { Atrial natriuretic } \\
\text { factor }\end{array}$ & Senile cardiac amyloid \\
\hline ATTR & Transthyretin & $\begin{array}{l}\text { FAP; multiple point mutations } \\
\text { Senile systemic cardiac }\end{array}$ \\
\hline AGel & Gelsolin & FAP-Finnish \\
\hline AApoA1 & Apolipoprotein A1 & FAP-Iowa (Irish) \\
\hline ACys & Cystatin C & Hereditary cerebral angiopathy with bleeding \\
\hline AFibA & Fibrinogen A a & $\begin{array}{l}\text { Nonneuropathic hereditary amyloid with renal } \\
\text { disease }\end{array}$ \\
\hline ALys & Lysozyme & $\begin{array}{l}\text { Nonneuropathic hereditary amyloid with renal } \\
\text { disease }\end{array}$ \\
\hline
\end{tabular}

Table 1. Abbreviated classification of amyloid (Sipe \& Cohen, 1998) 
$\beta_{2} \mathrm{M}$ amyloidosis is associated with patients who are maintained on hemodialysis for more than 7 years. Familial transthyretin-associated (ATTR) patients with normal plasma transthyretin develop senile systemic amyloidosis with predominant cardiac involvement, whereas patients with genetically variant transthyretin develop familial amyloid polyneuropathy (FAP), usually with systemic amyloidosis (Berg et al., 1993; Kennedy \& Patel, 2000). Table 1 shows the most common amyloid proteins and associated clinical syndromes (Sipe \& Cohen, 1998).

Approximately $9 \%$ to $15 \%$ of amyloidosis is of the localized type, which usually consists of AL amyloid (Passerotti et al., 2008). In localized idiopathic AL amyloidosis, localized deposition of amyloid is regarded to be the result of local synthesis rather than the deposition of light chains produced elsewhere in the human body (Yiotakis et al., 2009). The benign nature of localized amyloidosis suggests that a localized clone of plasma cells producing an amyloidogenic light chain may represent the pathogenetic mechanism of this disease, which appears to be a form of plasma cell dyscrasia (Berg et al., 1993).

Histologically, amyloid is extracellular deposits of insoluble, homogenous, amorphous, acellular, eosinophilic and proteinaceous material with a well-defined $\beta$-pleated sheet ultrastructure (Figure 1). Lymphocytes, plasma cells, and foreign body giant cells may be seen in the surrounding tissue in localized amyloidosis. Infiltration of plasma cells observed near localized amyloid deposits suggests local production of the amyloid precursor protein. Immunohistochemical and molecular genetic studies have characterized clonal plasma cell populations associated with local amyloid deposits, and have matched the amyloid protein with DNA sequencing of the plasma cell clone (Biewend et al., 2006). These abundant plasma cells are not seen in systemic AL amyloidosis, but rather the circulating light chain proteins are gathered in specific organs. Giant cells frequently accompany localized amyloid deposits. The role of these giant cells is unclear; they may actively participate in amyloid fibril formation by uptake and modification of the precursor protein, or they may be part of a foreign body reaction in an attempt by the body to remove amyloid (O'Halloran \& Lusk, 1994; Xu et al., 2005).

Classically, amyloid can be distinguished from other eosinophilic infiltrates via its applegreen birefringence when stained with Congo red and viewed under polarized light (Figure 2). This feature is specific but not sensitive. If the specimen loses its affinity for Congo red after exposure to potassium permanganate, this suggests an AA type amyloid deposit (Pentenero et al., 2006). Immunohistochemistry can differentiate kappa light chains from lambda light chains in AL type amyloidosis as well as excluding AA (inflammation-derived) and ATTR (transthyretin-derived) amyloid chains. Because of deposition of the variable regions of light chains, AL amyloid stains positive with commercially available antibodies only in approximately $40 \%$ of cases. Thus, negative immunostaining does not exclude AL amyloid. Isolation of amyloid with biochemical characterization by amino acid sequencing is the best way to confirm the AL type, but this is a very elaborate and time-consuming method and is not useful in normal practice (Bartels et al., 2004). Eventually these studies do not have much influence on patient management, since the number of additional biopsies and the treatment of localized amyloidosis do not differ whether the type of amyloidosis is known or not. Electron microscopy shows that all amyloid subtypes are composed of 7.5-10 $\mathrm{nm}$ wide linear, nonbranching tubular protein fibrils loosely arranged in a meshwork (O'Halloran \& Lusk, 1994).

It is important to perform detailed investigations at diagnosis to rule out a systemic process. General blood examination (hemoglobin, creatinine, total protein, albumin, bilirubin, 
alkaline phosphatase), general urine examination (creatinine clearance, proteinuria), ECG, echocardiography, abdominal USG should be undertaken (Bartels et al., 2004). Serum and urine analysis to detect the presence of a monoclonal paraprotein composed of amyloid light chains should also be performed. Serum or urine "Bence Jones proteins" will be found in up to $88 \%$ of patients with primary systemic amyloidosis and $100 \%$ of patients with multiple myeloma-associated systemic amyloidosis (Fahrner et al., 2004). If electrophoresis fails to demonstrate paraproteins, immunelectrophoresis should be considered (Kyle \& Bayrd, 1975). Collagen vascular diseases, tuberculosis, and multiple myeloma (rheumatoid factor, antinuclear antibody, tuberculosis skin test, and chest radiograph) should also be excluded (Friedman et al., 2002). Some authors advocate extensive investigations for patients who present with localized upper aerodigestive tract amyloidosis. Invasive procedures including labial salivary gland (LSG) biopsy, aspiration of abdominal fat, bone marrow biopsy, and rectal biopsy (positive in $84 \%$ of the cases) have been suggested as methods to exclude systemic amyloidosis. However, as the diagnostic yield is very low, some authors believe that invasive investigations are not indicated (Green et al., 2000). Fine-needle aspiration of abdominal fat pad (FNAFP) is less invasive compared to tissue biopsies and in a recent report, the estimated sensitivity and specificity of FNAFP was found to be $75 \%$ and $92 \%$, respectively. Based on results of follow-up biopsies and compelling clinical findings, others

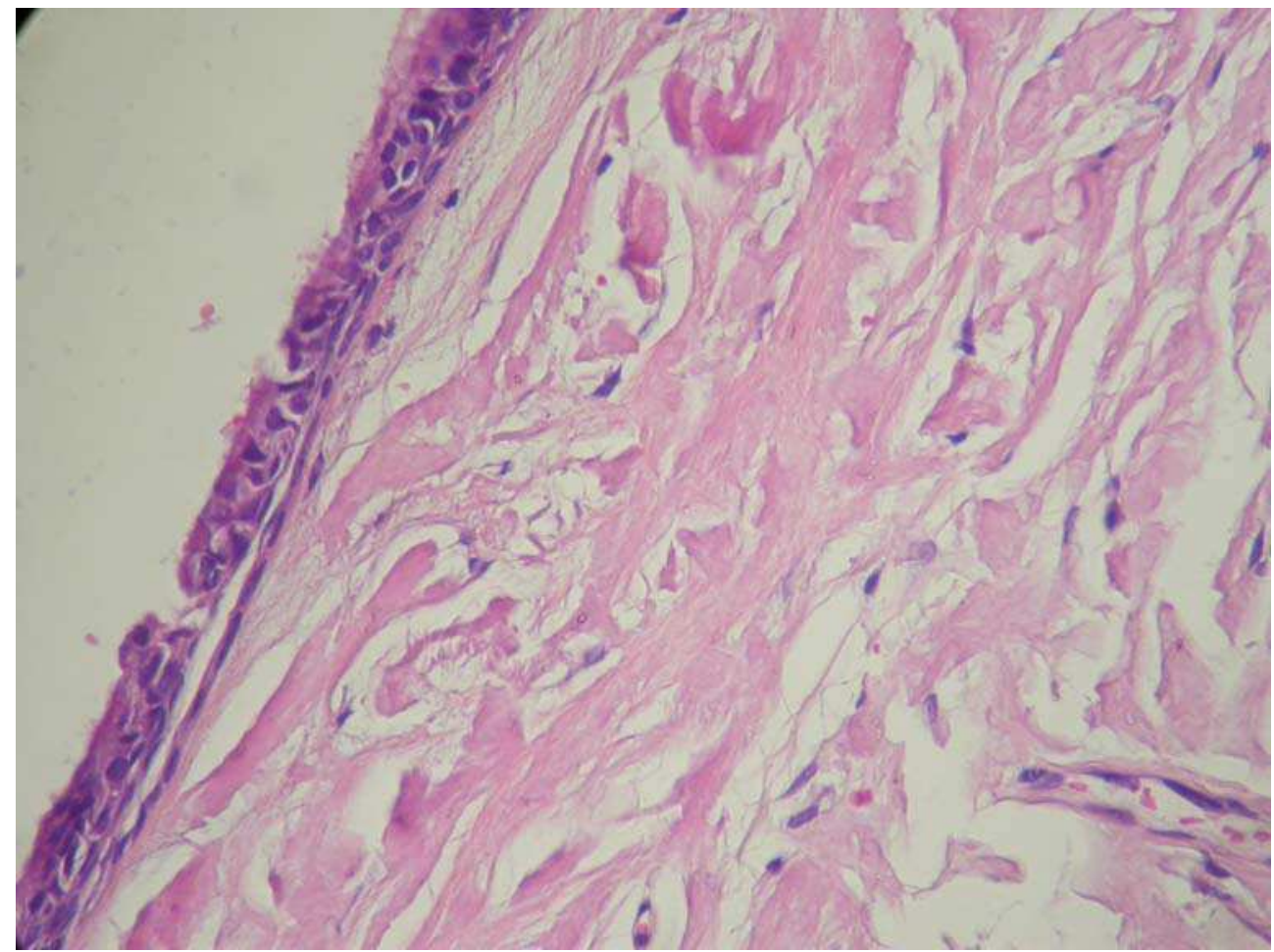

Fig. 1. In an excisional biopsy of localized amyloidosis of nasopharynx, bright pink homogenous, amorphous, acellular, eosinophilic material is seen in the submucosa (hematoxylin eosin, X40) (Özdemir et al., 2010) 
have reported specificity of $100 \%$ and sensitivity in the range of $58-88 \%$. The overall simplicity and ease of the procedure makes FNAFP the initial technique of choice for the diagnosis of systemic amyloidosis (Ansari-Lari \& Ali SZ, 2004). 123I-SAP scintigraphy is another non-invasive test to confirm or rule out occult systemic amyloidosis. However, in a few cases, 123I-SAP scintigraphy can be normal despite systemic amyloidosis with small amyloid deposits. The scintigraphy combined with LSG biopsy gives the clinician valuable information about the local or systemic character of amyloid deposits (Maulin et al. 1997).

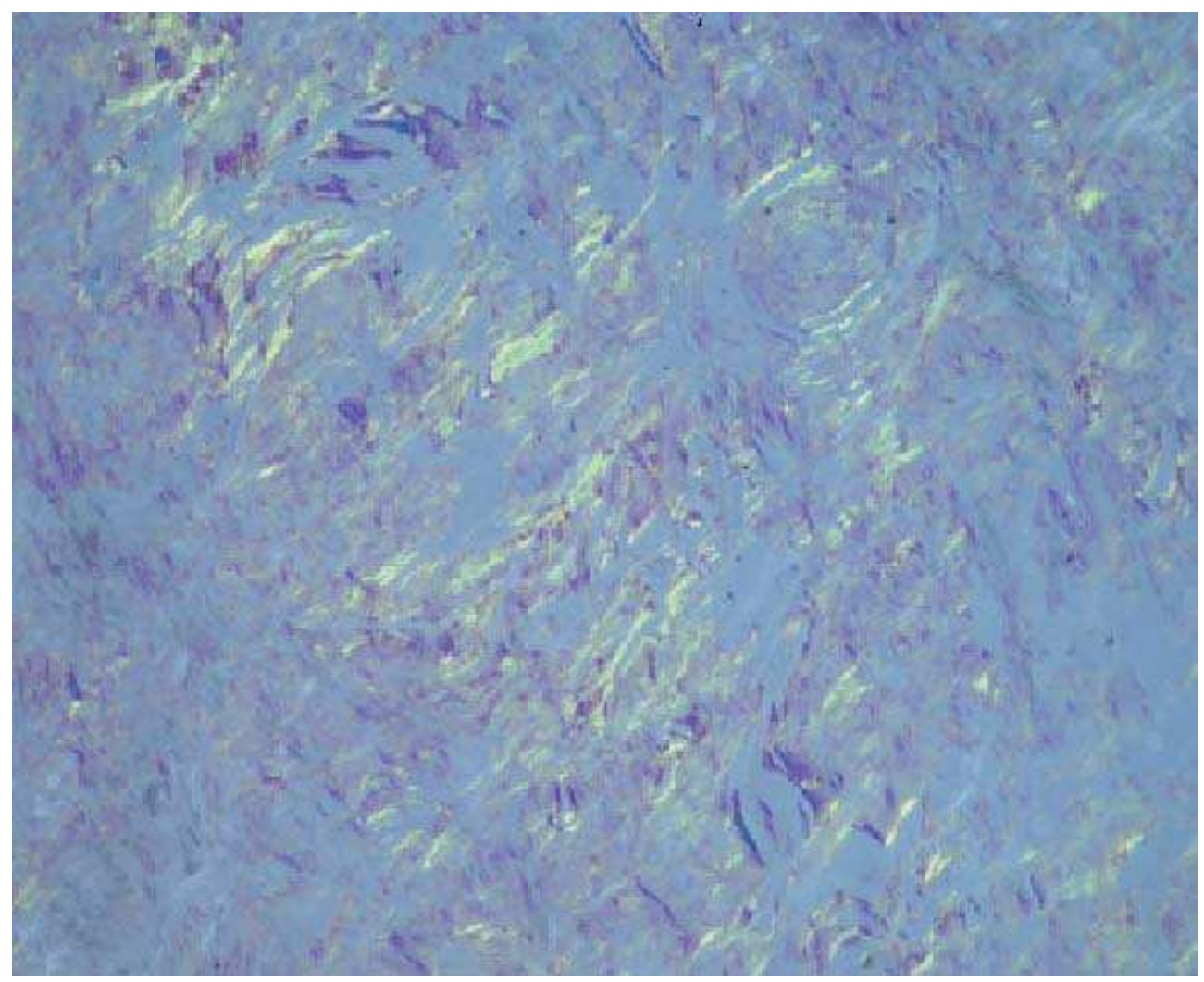

Fig. 2. Apple-green birefringence under polarized light (Congo-red, polarization microscope, $\times 20$ ) (Akyıldız et al., 2009)

When the diagnosis of localized amyloidosis is finally validated, the risk of further local progression exists, but the risk of systemic progression is low. In fact only three studies have possibly reported localized amyloidosis progressing to systemic disease. Some confusion still exists in the literature, since submucosal progression from laryngeal deposits to the tracheal, bronchial, or gastrointestinal tract is sometimes equated with systemic involvement. In the absence of a systemic involvement or a hematological malignancy, multifocal involvement of the aerodigestive tract should not be considered as systemic dissemination. In this regard, a full endoscopic assessment of the involved tract is necessary in order to clearly determine the number of sites affected by the process, to exclude an 
associated neoplasm and to anticipate the outcome. Due to the markedly shortened life expectancy in patients with systemic forms of amyloidosis, it is obligatory to differentiate systemic disease from the localized type (Paccalin et al., 2005).

Magnetic resonance imaging (MRI) is the technique of choice to demonstrate the most specific features of amyloidosis. Typically, the amyloid deposits have intermediate T1weighted signal intensity and low T2-weighted signal intensity, similar to skeletal muscle. This is secondary to the $\beta$-pleated structure of the amyloid deposits that occurs as protein fibrils in a parallel sheetlike configuration, similar to the organization of skeletal muscle fibers (Gilad et al., 2007). MRI taken before and after excision, helps in the evaluation and follow-up of the deposits, and can prevent further endoscopic examination (Chin et al., 2004).

Computed tomography (CT) scanning can discriminate between localized and diffuse disease in patients with amyloidosis of the respiratory tract (Chin et al., 2004). On CT scans, amyloid deposits appear as relatively well-defined, submucosal, homogenous masses, usually demonstrating different forms of calcification (Figure 3).

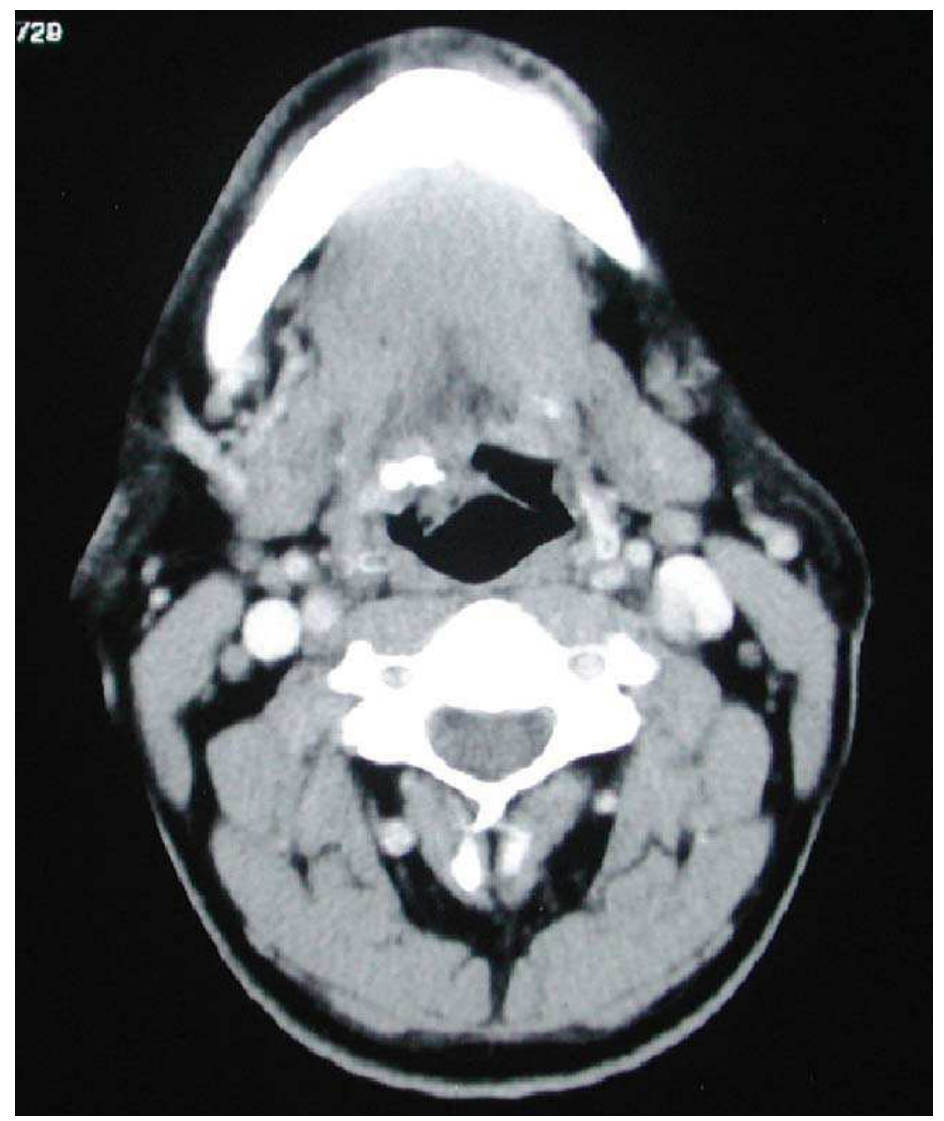

Fig. 3. CT scan of a lesion on the right side of the tongue base. Calcification is seen within the lesion. (Akyıldız et al., 2009) 
Although the amyloid itself does not enhance with contrast material administration, peripheral enhancement in the region of the amyloid deposits has been noted. This may be caused by the foreign-body giant cell reaction that is evoked around the amyloid deposits. The lack of enhancement of the amyloid deposits helps to distinguish them from cellular tumors, all of which enhance to varying degrees (Chin et al., 2004).

The low risk of subsequent systemic disease does not mean that localized amyloidosis is always benign. Although most patients remain free of disease, a few others have symptomatic recurrences, sometimes after many symptom-free years. Complications and fatal local progression have been reported despite optimal symptomatic treatment in respiratory tract and laryngeal amyloidosis because of recurrent obstruction, progressive respiratory failure or fatal hemorrhage (Gean-Marton et al., 1991).

Localized amyloidosis in the head and neck is a rare and benign disease. However $90 \%$ of the patients with systemic amyloidosis will develop amyloid deposits in the upper aerodigestive tract. Owing to its poor prognosis, the latter condition should be differentiated from primary localized amyloidosis of the head and neck. Localized amyloidosis may involve any site in the head and neck including the orbit, nose, paranasal sinuses, nasopharynx, oropharynx, tonsils, oral cavity, salivary glands, tongue, tracheobronchial tree and larynx (Passerotti et al., 2008; Penner \& Muller S, 2006). The larynx is the most common site of involvement and is rarely associated with systemic disease. In contrast, amyloid macroglossia is usually associated with systemic AL amyloidosis, either plasma cell dyscrasia or multiple myeloma. Most other locations in the head and neck are extremely rare with limited cases reported (Penner \& Muller S, 2006).

\section{Localized laryngeal amyloidosis}

Localized laryngeal amyloidosis accounts for $0.2 \%$ to $1.5 \%$ of benign laryngeal tumors (Ma et al., 2005). The first case of localized laryngeal amyloidosis was documented by Borow in 1873. McAlpine and Fuller, in a review of the literature, found 235 cases of localized amyloidosis of the upper and lower respiratory tracts, and the larynx was involved in 177 cases (75\%) (Nandapalan et al., 1998, as cited in McAlpine \& Fuller, 1964). Until 1990, only approximately 300 cases of upper airway amyloidosis were reported in the literature. This condition most commonly occurs in the fourth to sixth decades of life, with a male-female predominance of 3:1 (Ma et al., 2005).

The precise etiology and pathogenesis of laryngeal amyloidosis remain unknown. There is no definite established link with smoking, drinking, vocal abuse or recurrent infection (Ma et al., 2005). A large percentage of these patients also have significant reflux esophagitis. Amyloid deposits can result from chronic inflammatory process, and gastroesophageal reflux may be the cause in these cases.

Laryngeal amyloidosis most frequently presents with progressive dysphonia. Other complaints are dysphagia, dyspnea with exertion, choking, occasional aspiration, cough, fullness in the throat or globus sensation and rarely, hemoptysis (Bartels et al., 2004; Kennedy\& Patel, 2000; Yiotakis et al., 2009).

The gross appearance usually suggests a mucosally covered mass. The initial diagnosis is thought to represent a malignant neoplasm in most patients. Furthermore, at laryngoscopy and frozen section biopsy, the diagnosis may suggest only granulation tissue or a foreign body type of reaction and it may not be until after the permanent sections are analyzed that amyloidosis is considered (Kennedy\& Patel, 2000). 
The lesion is usually a firm, nonulcerated yellow, orange or gray submucosal nodule, mass or a pedunculated polypoid lesion. Amyloid deposits are most commonly located in the false vocal cords $(55 \%)$ and ventricles $(36 \%)$, less commonly in the subglottis $(36 \%)$, vocal folds $(27 \%)$, the aryepiglottic folds $(23 \%)$ and anterior commissure $(14 \%)$ (Mitrani \& Biler, 1985). It is frequent to have multiple laryngeal sites, or even, that of the aerodigestive tract, and tongue and trachea are the ones most frequently associated with laryngeal amyloidosis and, in such cases, systemic involvement is also more common (Passerotti et al., 2008). A case of laryngocele caused by localized laryngeal amyloidosis has been reported in the literature (Cankaya et al., 2002). Only one case of localized AL-type hypopharyngeal amyloidoma has been reported to date. (Ghekiere et al., 2003). Two other cases of localized amyloidosis of hypopharynx were secondary to multipl myeloma (Chadwick et al, 2002; Hammami et al, 2010)

Four histological patterns of laryngeal amyloidosis have been described. These include amorphous random masses, deposits around blood vessels, deposits in continuity with the basilar membrane of seromucinous glands, and deposits within adipose tissue (Gallivan \& Gallivan, 2010).

Laryngeal amyloidosis is usually associated with amyloid protein of the light chain (amyloid L; AL) type. Restricted light chain staining (lambda or kappa) in both plasma cells and the amyloid has been observed in cases of laryngeal amyloidosis. In one series, more than $60 \%$ of laryngeal deposits displayed a lambda light chain staining pattern, and $25 \%$ a kappa pattern. (Lewis et al., 1992; Ma et al., 2005).

Diagnosis should focus on evaluating the extent of local amyloidosis and on ruling out systemic involvement. Macroscopic examination of the larynx should be performed by indirect videolaryngostroboscopy. A thorough voice analysis is also required.

Radiological examination involves CT and MRI. On CT scans, laryngeal amyloidosis presents with submucosal and homogeneous amyloid deposits which are not associated with the cartilage changes. These deposits are firm lesions that tend to occur in the supraglottic larynx (Figure 4), although all laryngeal sites may be affected (Bartels et al., 2004). CT two-dimensional reconstruction images, along with their axial views, are found to be more helpful than any other scan in mapping the location of the amyloid before surgery as well as in planning the time of the surgery (Kennedy\& Patel, 2000). The differential diagnosis includes other submucosal diseases such as laryngeal sarcoidosis, lymphoma and pseudotumor. Submucosal lesions such as paragangliomas and hemangiomas are more localized on CT scans and MR images, and the entire lesion enhances rather than periphery (Bartels et al., 2004). However, even though the radiological studies are helpful, amyloidosis is usually not included in the differential before the material for biopsy is obtained by direct laryngoscopy (Kennedy \& Patel, 2000).

Systemic work-up should include a thorough history (including family history), physical examination (enlargement of spleen or liver, cardiac failure, edema), laboratory screening (levels of hemoglobin, serum creatinine, bilirubin, total protein, albumin, alkaline phosphatase, and proteinuria and a search for monoclonal proteins in serum and urine). ECG, echocardiography, and at least one other biopsy of a different site of the body, preferably the rectum or abdominal subcutaneous fat tissue (Bartels et al., 2004). Use of 123ISAP scintigraphy may be helpful, especially if combined with labial biopsy (Maulin et al., 1997).

Diagnostic work-up should also look for collagen vascular diseases, tuberculosis, and multiple myeloma (rheumatoid factor, antinuclear antibody, tuberculosis skin test, chest 


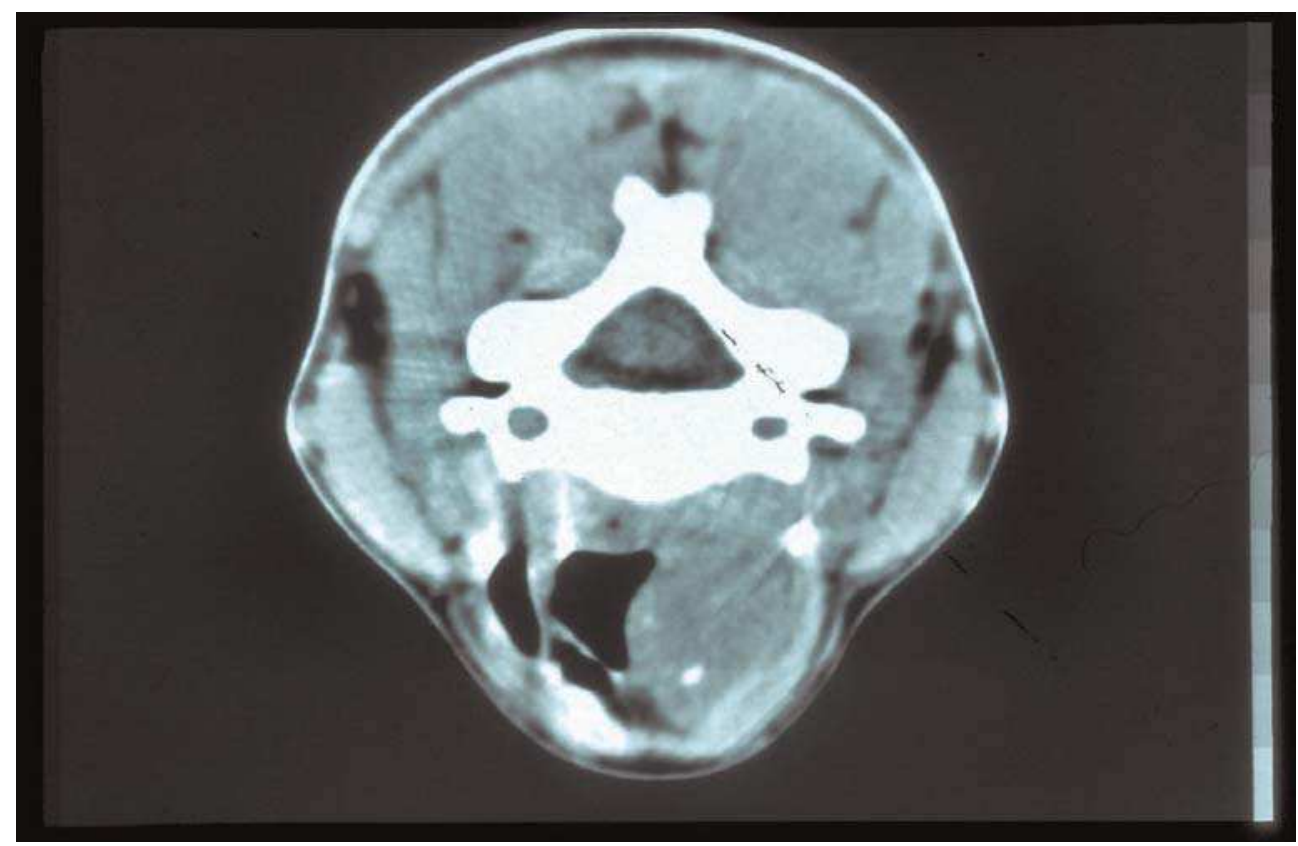

Fig. 4. Amyloidosis localized in supraglottic larynx. In this case thyroid cartilage appeared intact and no nodal involvement was detected (Yiotakis et al., 2009)

radiograph). The differential diagnosis should also include metastatic medullary thyroid cancer, laryngeal sarcoidosis, benign laryngeal polyps, laryngeal malignancies, benign minor salivary gland tumors and chondromas (Friedman et al., 2002)

The larynx is rarely the first location of systemic amyloidosis; however, systemic amyloidosis should never be ruled out from the differential diagnosis because of its potentially poor prognosis. In a case with localized laryngeal amyloidosis, systemic amyloidosis developed after an 8-year period, therefore yearly visits with a follow-up period of at least 10 years is recommended. Yearly monitoring of the presence of monoclonal free light chains in serum and urine may be helpful in detecting progression into systemic AL amyloidosis at an earlier stage of the disease (Bartels et al., 2004).

Laryngeal involvement may be a part of laryngo-tracheobronchial amyloidosis (LTBA) causing airway obstruction, hemoptysis, chronic cough, recurrent respiratory infections, dysphonia and dysphagia. LTBA is usually a primary, localized form of the disease, with deposits of AL amyloid fibrils. This evidence, together with the presence of plasma cells in and around amyloid deposits, may suggest that localized plasma cell dysfunction is responsible for this pathology. The precise etiology of primary localized airway amyloidosis still remains unclear, and the most recent hypothesis about its origin involves derangement of immunoregulation after recurrent or prolonged antigen challenge. Others have speculated that idiopathic production of structurally abnormal immunoglobulins by monoclonal plasma cells may overwhelm the clearing mechanisms leading to deposition of their cleavage products in the airway submucosa.

Classifying patients in a series of 32 LTBA cases showed purely laryngeal involvement in $12.5 \%$ of cases, isolated tracheal localization in $3 \%$ of cases, laryngo-tracheal amyloidosis (or 
"proximal airway disease") in $28 \%$ of cases, tracheobronchial disease (or "mid and distal airway disease") in $44 \%$ of cases, and extensive involvement of the entire laryngotracheobronchial tree in $12.5 \%$ of cases. A full endoscopic assessment of the involved tract clearly defines the number of sites affected by the process.

The endoscopic appearance of LTBA lesions can be classified as submucosal plaques and nodules, pseudotumor or tumor-like appearance, circumferential wall thickening. These appearances represent different stages of the same process of amyloid deposition. In fact, it seems to start with the formation of submucosal yellowish plaques, seen nearly everywhere in the tracheobronchial tree. Then lesions grow progressively in a confluent manner leading to a circumferential thickening or pseudotumor appearance. It is believed that these different endoscopic appearances have no prognostic implications, but effect the surgical options. In a pseudotumor mass or a circumferential wall thickening, mechanical resection and/or dilatation coupled with transmucosal Nd:YAG laser treatment with low power and high energy density are recommended. On the other hand, submucosal plaques, particularly when located at the glottic or subglottic levels, should be treated by a mucosa-sparing approach or by $\mathrm{CO}_{2}$ laser, thus minimizing scar tissue formation and subsequent complications (Piazza et al., 2003).

Localized laryngeal amyloidosis is a slowly progressive disease that should be treated according to the complaints of the patient. The indication for treatment is not determined by the presence of amyloid deposits, but the symptoms these deposits result in, such as dysphonia or dyspnea. Bronchoscopy is important to identify subglottic amyloid deposits and more distal tracheal or bronchial lesions. While the prognosis for laryngeal amyloidosis is usually good, death has rarely been reported. This usually occurs from diffuse tracheobronchial disease with pulmonary failure (Lewis et al., 1992).

The primary treatment described in localized laryngeal amyloidosis is endoscopic surgical removal of deposits that interfere with laryngeal or airway function, although extensive surgical procedures have been performed, depending on the size of the lesions. The location and size of the amyloid deposits should determine the surgical instruments of choice. Biopsy specimens are preferably removed by cold endoscopic excision. The specimens can be examined more minutely if no carbonization is present. Cold endoscopic excision is preferable for the removal of small deposits and those located at critical anatomic sites such as the true vocal cords. In these cases, a standard cordotomy is performed, after which the cheese-like contents can be taken out of the subepithelial space, and then the epithelial flap is glued back. In the same way, coring out subglottic lesions has a lasting and effective result. $\mathrm{CO}_{2}$ laser or powered instrumentation is usually used in supraglottic deposits. The epithelium is excised with these techniques. This may be the reason why supraglottic lesions tend to recur (Bartels et al., 2004).

Because of the propensity of amyloid to infiltrate blood vessels, cold resection of amyloid lesions may be complicated by bleeding. $\mathrm{CO}_{2}$ laser excision may be advantageous, but if used in very extensive lesions, there may be scarring. In very large lesions, external approaches, employing laryngofissure for treatment of diffuse subglottic and tracheal amyloidosis have been used. Repeated excision and curettage may be necessary to achieve stabilization of lesions and subsequent decannulation of those patients who are tracheotomy dependent (Gallivan \& Gallivan, 2010). Large supraglottic amyloid deposits, can be handled by supraglottic laryngectomy, or, by a more conservative approach, a lateral supraglottic procedure can be used (Kennedy \& Patel, 2000). Local or systemic steroids are ineffective in controlling or reversing lesions of amyloidosis. 
Gallivan and Gallivan report in their article that at the airway clinic they work with, 8 of 10 patients (3 laryngeal and 7 tracheobronchial recurrent amyloidosis cases) had achieved disease stability with low dose radiation. (Gallivan \& Gallivan, 2010). In another recent case report, a case of localized laryngeal amyloidosis involving false vocal cord was treated with surgical debulking and adjuvant external beam radiation to a dose of 45 Gy (Neuner et al., 2010).

There have been several proposed mechanisms by which radiation exerts its effects on amyloid deposits. One theory is that localized radiation therapy has a destructive effect on local abnormal plasma cells, which tend to be low dose radiation sensitive, as has been shown in patients with multiple myeloma and plasmacytomas. However, the amyloid deposits in laryngo-tracheobronchial amyloidosis contain scarce plasma cells, so a radiation effect on plasma cell function or turnover is unlikely to be the only mechanism of action. Other possibilities include a radiation effect on local vascular structures or induction of immune responses against the deposits by causing local inflammation. In addition, there may be other blood, tissue, or $\mathrm{pH}$ factors in the local milieu that mediate the response (Neben-Wittich et al., 2007).

Localized laryngeal amyloidosis tends to recur and it usually takes a number of years until the disease is stabilized. A detailed history of current symptoms and local examination of the larynx should be encountered with yearly follow-ups, and local recurrences should be treated as conservative as possible. There has been no report of malignant change in amyloid tumor however one must be aware of the possibility of a subsequent development of systemic amyloidosis (Friedman et al., 2002).

\section{Localized nasopharyngeal amyloidosis}

Localized amyloidosis occurs most commonly in the head and neck region. Among the sites, larynx is affected most frequently $(61 \%)$, followed by oropharynx $(23 \%)$, trachea $(9 \%)$, and orbit $(4 \%)$. Only $3 \%$ of cases occur in the nasopharynx. Up to 2007 there were only 14 reported cases (Panda et al., 2007). A Pubmed search up to the present revealed 4 more cases including the case we had reported in 2010. (Geller et al., 2010; Özdemir et al., 2010; Passerotti et al., 2008; Zhuang et al., 2015) Table 2 shows a list of all of the reported cases.

The presentation of head and neck amyloidosis varies according to the site of involvement. A patient with nasopharyngeal amyloidosis may present with postnasal discharge, nasal obstruction, recurrent epistaxis (due to vessel wall invasion), dysphagia, foreign body sensation in the throat, voice change, eustachian tube dysfunction and secondary ear problems such as conductive hearing loss due to middle ear effusion. Lesions appear as yellowish, mucosa covered, irregular polypoidal masses (Patel et al., 2002).

On CT scan, amyloid deposits appear as relatively well-defined, submucosal, homogenous masses, usually demonstrating different forms of calcification (Figure 5). The mass exhibits minimal, if any, enhancement after administration of contrast. On MRI, the submucosal location and distinctive hypointensity on T2-weighted images excludes many of the other differential diagnosis. (Gean-Marton et al., 1991) Dynamic MR further defines the vascular changes due to localized amyloid deposition (Asaumi et al., 2001).

Nasopharyngeal amyloidosis is generally a slow growing, benign tumor, but it may be locally aggressive and produce osteolysis and even invade the skull base. CT and MRI are helpful in revealing any bony destruction or intracranial extension (Patel et al., 2002). 


\begin{tabular}{|c|c|c|c|c|}
\hline Authors & Year & Age/Sex & Site of Involvement & Symptoms \\
\hline Kramer & 1935 & - & NF & Nasal obstruction \\
\hline Johner & 1972 & - & NF & Nasal obstruction \\
\hline Simpson & 1984 & $29 / \mathrm{F}$ & NF & Postnasal discharge, glue ear \\
\hline Zack Zonk & 1984 & $14 / \mathrm{M}$ & NF & Hearing loss, glue ear \\
\hline Gean Marton & 1991 & - & NF ( 3 cases $)$ & Nasal obstruction, glue ear \\
\hline Hegarty & 1993 & - & NF with skull base erosion & Nasal obstruction, postnasal discharge \\
\hline Panda & 1994 & $82 / \mathrm{M}$ & NF & Oral bleeding \\
\hline Dominguez & 1996 & $13 / \mathrm{F}$ & NF and soft palate & Nasal obstruction, oral bleeding \\
\hline Lim & 1999 & $42 / \mathrm{F}$ & NF & Nasal obstruction \\
\hline Pitkaranta & 2000 & - & NF & Nasal obstruction \\
\hline Patel & 2002 & - & NF & Hearing loss, glue ear \\
\hline Zhuang & 2005 & - & NF and cervical LN & Nasal obstruction, cervical mass \\
\hline Panda & 2007 & $43 / \mathrm{M}$ & NF, oropharynx & $\begin{array}{l}\text { Nasal obstruction, foreign body } \\
\text { sensation of throat }\end{array}$ \\
\hline Passerotti & 2008 & $55 / \mathrm{F}$ & NF, Tonsil pillar, larynx & Hoarseness, dysphonia, dysphagia \\
\hline Geller & 2010 & $62 / \mathrm{F}$ & NF and nasolacrimal duct & Nasolacrimal duct obstruction \\
\hline Özdemir & 2010 & $67 / \mathrm{F}$ & NF and cervical LN & Nasal obstruction, cervical mass \\
\hline
\end{tabular}

F: Female, M: Male, NF: Nasopharynx, LN: Lymph node

Table 2. Reported cases of nasopharyngeal amyloidosis

Diagnosis of nasopharyngeal amyloidosis is made with histopathological examination of amyloid deposits in biopsy specimens as mentioned earlier. Systemic involvement should be ruled out. In the absence of a systemic disease, localized nasopharyngeal amyloidosis has an excellent prognosis.

Surgery is reported to be the choice of therapy. Transpalatal approach or nasopharyngeal curettage is preferred (Özdemir et al., 2010). Bleeding due to the loss of vascular integrity caused by amyloid infiltration of the blood vessels may be a major complication during surgery (Patel et al., 2002). Excision of the amyloid deposits should only be considered if they cause morbidity. However if localized amyloidosis do not cause morbidity, conservative treatment with careful observation is suggested (Domínguez et al., 1996).

In the English literature two cases of localized nasopharyngeal amyloidosis associated with lymph node involvement in the neck are reported (Özdemir et al., 2010; Zhuang et al., 2005). This presentation mimics nasopharyngeal carcinoma with neck metastases. In such a case, diagnosis of localized amyloidosis should be confirmed with biopsy of nasopharyngeal mass and fine needle aspiration biopsies of the neck masses. If asymptomatic, the removal of the neck masses showing amyloid deposits is not necessary.

Nasopharyngeal amyloidosis may coexist with carcinoma of nasopharynx. In a series of 434 cases of nasopharyngeal carcinoma, amyloid deposits were found in $12 \%$ of the cases (Munichor et al., 2000, as cited in Pratap et al., 1984). In another recent case report of nasopharyngeal carcinoma with cervical metastasis, the blind biopsies obtained from nasopharynx and fine needle aspiration biopsy (FNAB) of the metastatic cervical lymph nodes revealed carcinoma with amyloid deposits. Authors draw attention to the fact that a potential association of these two conditions may be more frequent than expected and diagnosis of carcinoma with amyloidosis can be made with the use of FNAB (Munichor et al., 2000). 


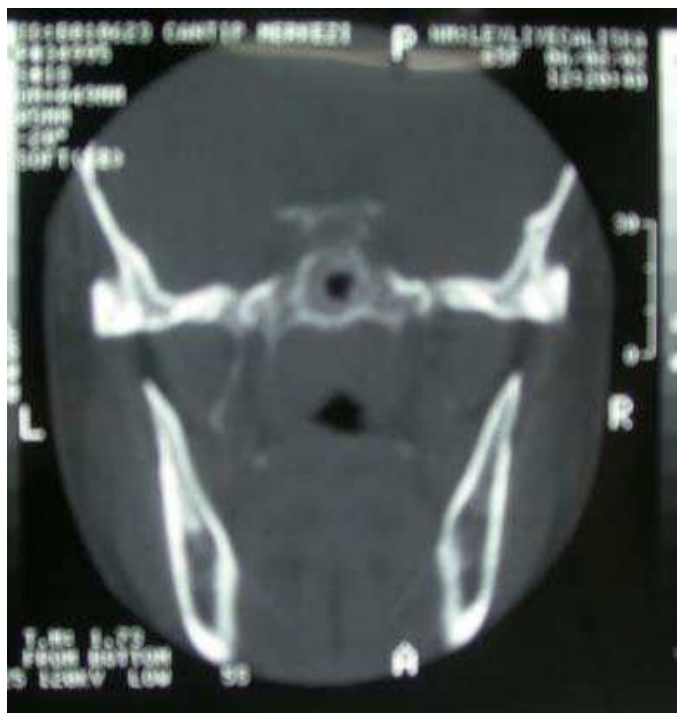

Fig. 5. In the CT scan, the nasopharynx is obliterated by a granular mass with irregular borders. No calcification is seen. Histological examination of the lesion revealed amyloidosis (Özdemir et al., 2010)

Sometimes, amyloid tumors in the nasopharynx can be difficult to treat and recur despite surgical excision. Less recurrence is reported following laser excision of localized amyloidosis (Simpson et al., 1984). Localized nasopharyngeal amyloidosis is a rare disease, for which slow progression and spontaneous regression is expected, therefore it is difficult to predict the outcome. Recurrent masses and extensive lesions involving the head and neck should be handled conservatively (Patel et al., 2002).

\section{Localized sinonasal amyloidosis}

Primary amyloidosis localized to the nose and/or paranasal sinuses is rare with only 27 reported cases in the English literature (Chin et al., 2004; Mufarrij et al., 1990; Paccalin et al., 2005; Pang et al., 2001; Prasad et al., 2009; Teo et al., 2003; Tsikoudas et al., 2001). Out of these 8 of them are solely localized to the nasal cavity (Pang et al., 2001).

Smooth, soft to firm, non tender, pale waxy gray, yellow or pale pink masses of amyloid deposits are found localized to the inferior concha or other parts of the lateral wall, the septum (Figure 6). The diagnostic nasal endoscopy is helpful in exploring yellowish polypoidal masses extending to the choana, though radiological imaging defines the disease more thoroughly (Prasad et al., 2009). Amyloid deposits are composed of AL, kappa or lambda light chain amyloid. Clinical presentation is often insidious, with symptoms that are slowly progressive over months to years prior to diagnosis. Presenting symptoms are nasal obstruction, nasal discharge, epistaxis and glue ear; facial pain and neuralgia can be seen in amyloidosis of the maxillary antrum (Paccalin et al., 2005; Pang et al., 2001).

The extent of the localized disease is best evaluated by CT and/or MRI scans. In CT scans, calcification seems to be a nonspecific finding. Besides this, in the paranasal sinuses, a "fluffy" appearance is noted in the sinonasal cavity bones adjacent to the amyloid deposits 
in a case. This could be a result of an osteoblastic reaction incited by the deposition of the proteinaceous amyloid fibrils in the submucosal layers of the sinonasal cavities. Although sinonasal calcifications can also be seen in inspissated secretions, fungal mycetomas, cartilaginous tumors, and olfactory neuroblastomas, the "fluffy" bone changes have not been seen with these diseases (Chin et al., 2004).

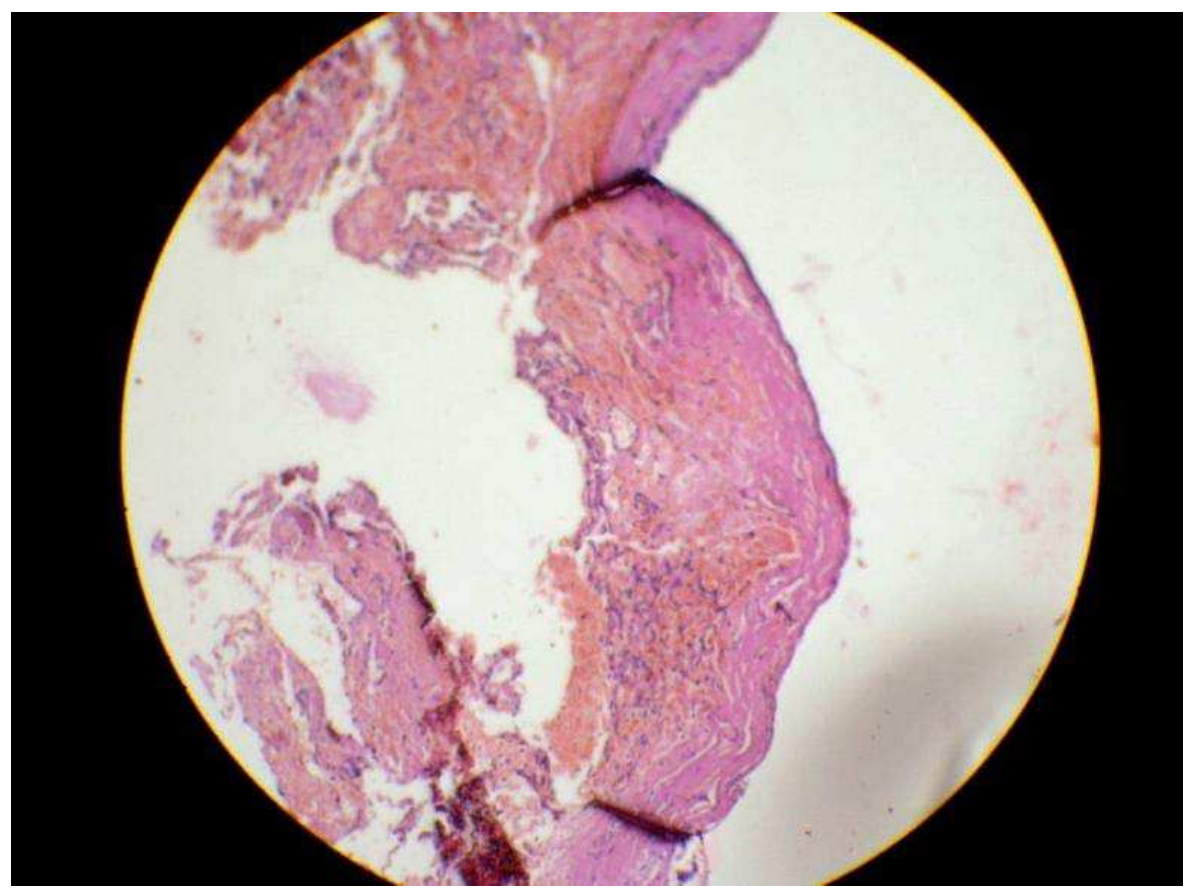

Fig. 6. Amyloid deposits beneath nasal mucosa (hematoxylin eosin) (Prasad et. al., 2009)

Systemic disease should be excluded with appropriate tests. Multifocal involvement is possible therefore endoscopic examination of the entire respiratory tract is indicated including nasopharynx, oropharynx, larynx and tracheobronchial tree. Medical treatment has been unsuccessful and radiotherapy is ineffective and contraindicated in this region. When the disease is symptomatic, conservative surgery is the only option, however recurrences are common (Tsikoudas et al., 2001). Simpson et al. reported that complete excision using the $\mathrm{CO}_{2}$ laser was satisfactory with no recurrence in a 14-year follow-up period, whereas incomplete excision resulted in recurrence (Simpson et al., 1984).

\section{Localized amyloidosis of the oral cavity and oropharynx}

Oral amyloidosis often appears with a variety of manifestations, such as multiple soft nodules that appear hemorrhagic or pink to yellow. Amyloidosis presents as a diffuse or a nodular mass mimicking a neoplasm such as granular cell tumors, schwannomas, neurofibromas and mucosal neuromas (Asaumi et al., 2001).

The tongue is the most frequently observed oral subsite, which almost always suggests systemic disease. This can cause a firm or rubbery macroglossia, manifested by increased 
tongue volume, tongue protrusion beyond the alveolar ridge, speech impairment, and dysphagia (Fahrner et al., 2004). The patients with macroglossia typically demonstrate scalloping of the lateral border of the tongue due to indentations from the teeth (Penner \& Muller, 2006). Yellow nodules or raised white lesions occurring predominately along the lateral border are also common (Fahrner et al., 2004). Sometimes petechiae, ecchymoses and hemorrhagic blisters can also be observed. The tongue involvement with numerous smooth surfaced, white-yellow nodules has been reported in cases of long term dialysis related amyloidosis (Pentenero et al., 2006). Amyloid of the tongue is usually secondary to primary amyloidosis with plasma cell dyscrasia, consisting of the monoclonal AL immunoglobulin light-chain amyloid. Additionally, macroglossia occurs in $26 \%$ to $83 \%$ of patients with multiple myeloma. For generalized macroglossia, besides amyloidosis; tuberculosis, lymphangioma, hypothyroidism, acromegaly, lingual infarction caused by giant-cell arteritis, idiopathic muscular hypertrophy, and Beckwith-Wiedemann syndrome should be considered in the differential diagnosis.

Localized amyloidosis of the tongue is rare and associated with AL type amyloidosis. So far, only thirteen cases have been reported in the English literature. (Biewend et al., 2006; Fahrner et al.,2004; Koren et al., 1998; Penner \& Muller, 2006; Simpson et al., 1984), although for four of these cases, a full evaluation for systemic disease was not documented. One of these cases was reported to develop Hodgkin's lymphoma 12 years after the diagnosis of localized amyloidosis (Penner CR \& Muller S (2006). Two of the cases presented with glossodynia and glossopyrosis with lesions which were thought to represent median rhomboid glossitis (Koren et al., 1998; Yamoka et al., 1978). One other patient presented with pyrosis of tongue and a well-circumscribed, rubbery, nodular mass in the tongue base (Akyıldiz et al, 2009). Others had discrete, firm, pink to yellowish, multiple or solitary nodular lesions on the tongue (Penner \& Muller, 2006). For nodular localized lesions, fibroma, lipoma, granular cell tumor, sarcoma, and salivary gland tumors are among the differential. MR images of tongue involvement of amyloidosis appear slightly low on T1weighted images and slightly high on T2-weighted images compared with T1-T2 images of residual normal tongue (Asaumi et al., 2001).

Localized amyloid of the tonsil is also rare and, to date there have only been thirteen reports in the world literature.(Green et al., 2000; López et al., 1996; Passerotti et al., 2008; Tsuji et al., 2008) Four of these cases also involve other parts of the Waldeyer's ring. (Green et al., 2000; Passerotti et al., 2008) In four reports amyloid was found to affect both tonsils (Green et al., 2000). Immunohistochemical investigations undertaken in some of the reports revealed AL type amyloidosis (López et al., 1996; Tsuji et al., 2008)

Localized amyloidosis of other sites of the oral cavity is extremely rare. Only 5 cases of localized amyloidosis involving palate have been reported to date. (Aono et al., 2009; Pentenero et al., 2006) One of these cases was found to be AA type of amyloidosis while others were AL type. Even though AA type of amyloidosis is usually secondary to chronic inflammatory diseases, the systemic work-up for this case was negative, and the case was considered a primary localized involvement of the palate. The authors hypothesized the role of the denture as a local chronic irritant agent (Pentenero et al., 2006). Lips (Simpson et al., 1984), gingiva (Maulin et al., 1997), lateral pharyngeal wall (Penner \& Muller 2006), floor of the mouth (Simpson et al., 1984) are other sites involved in various reports.

Although the presentation seems localized, amyloidosis of head and neck mucosal sites excluding larynx is often secondary to an underlying malignancy. In a series of 12 cases involving the tongue, pharynx, and cervical lymph nodes, 9 (78\%) were associated with malignancy or plasma cell dyscrasia. A referral to a hematologist is appropriate when a 
patient presents with lingual amyloidosis or other head and neck sites to exclude malignancy or systemic disease (Penner \& Muller, 2006).

\section{Localized amyloidosis of other sites of head and neck}

Although the parotid gland has been suggested as a possible site of involvement in systemic amyloidosis, only three cases of localized amyloid tumor involving the parotid gland without systemic involvement has been reported in the literature (Stimson et al., 1988; Nandapalan et al., 1998; Biewend et al., 2006). The immunohistochemical work-up for the first case demonstrated staining for immunoglobulin A, lambda and kappa light chains within the amyloid deposits and in the cytoplasm of the lymphocytes, and plasma cell aggregates (Stimson et al., 1988). The second case presented with enlarging, painless swelling of the right parotid region. FNAB of the mass nondiagnostic, but an MRI scan of the head and neck showed that both parotid glands were involved. A right parotidectomy for histological diagnosis was given, and the patient was asymptomatic in the follow-up (Nandapalan et al., 1998). The third case presented with the involvement of both parotid and submandibular glands. The lesions were excised and no recurrence was observed (Biewend et al., 2006).

As far as salivary structures are concerned, one other case of primary localized amyloidosis of the sublingual gland is reported. This case is also the first case of the oral cavity with primary localized amyloidosis consisting AA protein (Kurokawa et al., 1998).

Many cases of cutaneous amyloidosis have been reported in the literature, but only 4 primary localized cases involving the external auditory canal, and one case involving both external and middle ear were reported. The latter case was diagnosed with the biopsy of the external canal and the CT images of the middle ear were similar to the mass in the external ear canal. The patient was treated with regular cleansing and debridement of the ear canal to prevent irritation, deafness and secondary infection. The authors were reluctant to explore the middle ear, fearing to provoke postoperative dizziness or tinnitus, for this could end the patient's job as a roofer. Fourteen months after diagnosis, the disease remained confined to the involved ear (Gheriani et al., 2007). In the English literature, two other cases of hemodialysis-associated amyloidosis localized to external auditory canal have been reported (Yamazaki et al., 2011). Treatment should include local excision and debridement to prevent irritation, deafness, and secondary infection. Topical steroid therapy can also help limit the local inflammatory process (Gheriani et al., 2007).

To date, eight cases of primary cutaneous amyloidosis involving the auricular concha have been reported (Shimauchi et al., 2006). The nodules which appear pink to brown or red, are typically non-pruritic, slightly friable, but tend not to ulcerate. They may be present on both ears. This entity appears to have been described previously as collagenous papules of the ear. The patients do not have lesions of amyloidosis on other parts of the body and no systemic involvement is seen (Hicks et al., 1988). Skin biopsy provides the definitive diagnosis. An optimal biopsy specimen includes the epidermis, papillary dermis, and reticular dermis. The amyloid in nodular localized cutaneous amyloidosis is located in the reticular dermis and subcutaneous fat, and clearly differentiates nodular localized cutaneous amyloidosis from other forms of amyloidosis. A shave biopsy or other superficial samples may not include enough reticular dermis to complete the diagnosis (Biesbroeck \& Kauffman, 2010). Histologically amorphous materials are present in the widened dermal papillae positive for Congo red (Shimauchi et al., 2006). Procedures such as excision, curettage and electrodesiccation as well as laser treatment have provided satisfactory 
cosmetic results for nodular localized cutaneous amyloidosis. None of these treatment methods totally eradicates lesions, which can recur (Biesbroeck \& Kauffman, 2010).

Nodular localized primary cutaneous amyloidosis of the nose is very rare and five cases have been reported to date (Biewend et al., 2006; Blanc et al., 1985; Evers et al., 2007; Kakani et al., 2001) Nodular amyloidosis can be treated successfully with cold steel excision in combination with carbon dioxide laser. Cases of nodular localized cutaneous amyloidosis of the neck present with multiple subcutaneous neck nodules. A literature review showed five reported cases of subcutaneous nodular amyloidosis. Immunohistochemical analysis in one of these cases showed the amyloid deposits consisting of AL lambda light chains. Twentyfour months follow-up in this case showed minimal disease progression (Nguyen et al., 2001). Finally, amyloid may infiltrate the thyroid or other endocrine glands, but rarely causes endocrine dysfunction. However, local amyloid deposition in the thyroid gland is noted to have a close association with medullary carcinoma, being present in the stroma of $75 \%$ of medullary carcinoma. Therefore, a neck mass revealing amyloid should be investigated to rule out occult medullary carcinoma of the thyroid gland. (Nandapalan et al, 1998).

\section{Conclusion}

Localized amyloidosis in the head and neck is a benign disease, and should be differentiated from localized involvement of a systemic disease. Upper aerodigestive tract can be involved in $90 \%$ of the patients with systemic amyloidosis. Owing to its poor prognosis, the latter condition as well as localized amyloidosis should be recognized by otolaryngologists, and systemic investigations should be encountered in order to differentiate localized from systemic amyloidosis. Localized amyloidosis of head and neck tend to recur, and it usually takes a number of years until the disease is stabilized, therefore conservative management is the rule. If the disease is symptomatic, conservative surgery is essential, and yearly followups are recommended for at least 10 years. Local recurrences should be treated as conservative as possible. Asymptomatic disease usually requires no intervention. In the follow-ups, systemic amyloidosis should never be ruled out from the differential diagnosis. Early monitoring of the presence of monoclonal free light chains in serum and urine might be helpful in detecting progression into systemic amyloidosis at an earlier stage of the disease. Finally, localized amyloidosis of the head and neck is rare, therefore publication of more cases should be encouraged in order to contribute to the literature and develop appropriate strategies for management.

\section{References}

Akyıldız S, Doğanavsargil B, Göde S \& Veral A (2009). Solitary Amyloid Tumor of the Tongue Base. International Journal of Otolaryngology Vol: 2009

Ansari-Lari MA \& Ali SZ (2004). Fine-needle aspiration of abdominal fat pad for amyloid detection: a clinically useful test? Diagn Cytopathol. Mar;30(3), pp. 178-81.

Aono J, Yamagata K \& Yoshida H (2009). Local amyloidosis in the hard palate: a case report. Oral Maxillofac Surg. Jun;13(2),pp. 119-22.

Asaumi J, Yanagi Y, Hisatomi M, Konouchi H \&, Kishi K (2001). CT and MR imaging of localized amyloidosis. Eur J Radiol. Aug;39(2),pp. 83-7.

Bartels H, Dikkers FG, Van der Wal JE, Lokhorst HM \& Hazenberg BP (2004). Laryngeal amyloidosis: localized versus systemic disease and update on diagnosis and therapy. Ann Otol Rhinol laryngol. Sep;113(9),pp. 741-8. 
Berg AM, Troxler RF, Grillone G, Kasznica J, Kane K, Cohen AS \& Skinner M (1993). Localized amyloidosis of the larynx: evidence for light chain composition. Ann Otol Rhinol Laryngol. Nov;102(11), pp. 884-9.

Biesbroeck L \& Kauffman CL (2010). Amyloidosis, Nodular Localized Cutaneous, In: Medscape Reference, 2011, Available from: < http://emedicine.medscape.com/article/1102770-workup >

Biewend ML, Menke DM \& Calamia KT (2006). The spectrum of localized amyloidosis: a case series of 20 patients and review of the literature. Amyloid. Sep;13(3),pp. 135-42.

Blanc F, Triller R, Ferte JF, Itasse H, Schernberg C, Pluot M \& Kalis B (1985). Nodular primary localized cutaneous amyloidosis of the tip of the nose. Ann Dermatol Venereol.;112(9), pp. 701-2.

Cankaya H, Egeli E, Unal O \& Kiris M (2002). Laryngeal amyloidosis: a rare cause of laryngocele. Clin Imaging. Mar-Apr;26(2), pp. 86-8.

Chadwick MA, Buckland JR, Mason P, Randall CJ \& Theaker J (2002). A rare case of dysphagia: hypopharyngeal amyloidosis masquerading as a post-cricoid tumour. $J$ Laryngol Otol;116, pp. 54-56.

Chin SC, Fatterpeckar G, Kao CH, Chen CY \& Som PM (2004). Amyloidosis concurrently involving the sinonasal cavities and larynx. AJNR Am J Neuroradiol. Apr;25(4), pp. 636-8.

Domínguez S, Wienberg P, Clarós P, Clarós A \& Vila J (1996). Primary localized nasopharyngeal amyloidosis. A case report. Int J Pediatr Otorhinolaryngol. Jun;36(1), pp. 61-7.

Evers M, Baron E, Zaim MT \& Han A (2007). Papules and plaques on the nose. Nodular localized primary cutaneous amyloidosis. Arch Dermatol. Apr;143(4),pp. 535-40.

Fahrner KS, Black CC \& Gosselin BJ (2004). Localized amyloidosis of the tongue: a review. Am J Otolaryngol. May-Jun;25(3),pp. 186-9.

Friedman AD, Bhayani R, Memeo L \& Kuriloff DB (2002). Localized laryngeal amyloidosis. Otolaryngol Head Neck Surg. Nov;127(5)pp. 487-9.

Gallivan GJ \& Gallivan HK (2010). Laryngeal amyloidosis causing hoarseness and airway obstruction. J Voice. Mar;24(2),pp.235-9. Epub 2008 Dec 25.

Gean-Marton AD, Kirsch CF, Vezina LG \& Weber AL (1991). Focal amyloidosis of the head and neck: evaluation with CT and MR imaging. Radiology. Nov;181(2),pp. 521-5.

Geller E, Freitag SK \& Laver NV (2010). Localized Nasopharyngeal Amyloidosis Causing Bilateral Nasolacrimal Duct Obstruction. Ophthal Plast Reconstr Surg. Sep 23. [Epub ahead of print]

Ghekiere O, Desuter G, Weynand B \& Coche B (2003). Hypopharyngeal amyloidoma. Am J Radiol 181,pp. 1720-1721.

Gheriani H, Tewary R\& O'Sullivan TJ (2007). Amyloidosis of the external auditory canal and middle ear: unusual ear tumor. Ear Nose Throat J. Feb;86(2),pp. 92-3,106.

Gilad R, Milillo P \& Som PM (2007). Severe diffuse systemic amyloidosis with involvement of the pharynx, larynx, and trachea: CT and MR findings. AJNR Am J Neuroradiol. Sep;28(8),pp. 1557-8.

Green KM, Morris DP, Pitt M \& Small M (2000). Amyloidosis of Waldeyer's ring and larynx. J Laryngol Otol. Apr;114(4):296-8.

Hammami B, Mnejja M, Kallel S, Bouguecha L, Chakroun A, Charfeddine I \& Ghorbel A (2010). Hypopharyngeal amyloidosis: A case report. Eur Ann Otorhinolaryngol Head Neck Dis. May;127(2),pp. 83-5. Epub 2010 Mar 31.

Hicks BC, Weber PJ, Hashimoto K, Ito K Koreman DM (1988). Primary cutaneous amyloidosis of the auricular concha. J Am Acad Dermatol. Jan;18(1 Pt 1),pp.19-25.

Kakani RS, Goldstein AE, Meisher I \& Hoffman C (2001). Nodular amyloidosis: case report and literature review. Cutan Med Surg. Mar-Apr;5(2),pp. 101-4. Epub 2001 Mar 2. 
Kennedy TL \& Patel NM (2000). Surgical management of localized amyloidosis. Laryngoscope. Jun;110(6),pp.918-23.

Koren R, Veltman V, Halpern M, Szabo R \& Gal R (1998). Localized amyloid tumor of the tongue. A case report and review of the literature. Rom J Morphol Embryol. JanDec;44(1-4), pp.179-82.

Kurokawa H, Takuma C, Tokudome S, Yamashita Y \& Kajiyama M (1998). Primary localization amyloidosis of the sublingual gland. Fukuoka Igaku Zasshi. Jul;89(7),pp. 216-20.

Kyle RA \& Bayrd ED (1975).Amyloidosis: Review of 236 cases. Medicine 54,pp. 271-299.

Kyle RA \& Greipp PR. (1983). Amyloidosis (AL), clinical and laboratory features in 229 cases. Mayo Clin Proc 58,pp. 665-683.

Lewis JE, Olsen KD, Kurtin PJ \& Kyle RA (1992). Laryngeal amyloidosis: a clinicopathologic and immunohistochemical review. Otolaryngol Head Neck Surg. Apr;106(4) pp. 372-7.

López AM, Lorenzo PMJ, López BG \& Arnal MF (1996). Giant primary amyloidoma of the tonsil. J Laryngol Otol. Jun;110(6), pp. 613-5.

Ma L, Bandarchi B, Sasaki C, Levine S \& Choi Y (2005). Primary localized laryngeal amyloidosis: report of 3 cases with long-term follow-up and review of the literature. Arch Pathol Lab Med. Feb;129(2),pp. 215-8.

Maulin L, Hachulla E, Deveaux M, Janin A, Wechsler B, Godeau P, Rousset H, Barrier JH, Hatron PY, Devulder B, Huglo D \& Marchandise X (1997). 'Localized amyloidosis': 123I-labelled SAP component scintigraphy and labial salivary gland biopsy. QJM. Jan;90(1), pp.45-50.

Mitrani M \& Biller HF (1985). Laryngeal amyloidosis. Laryngoscope. Nov;95(11), pp. 1346-7.

Munichor M, Cohen H, Kerner H, Szvalb S \& Iancu TC (2000). Localized amyloidosis in nasopharyngeal carcinoma diagnosed by fine needle aspiration and electron microscopy. A case report. Acta Cytol. Jul-Aug;44(4),pp. 673-8.

Mufarrij AA, Busaba NY, Zaytoun GM, Gallo GR \& Feiner HD (1990). Primary localized amyloidosis of the nose and paranasal sinuses. A case report with immunohistochemical observations and a review of the literature. Am J Surg Pathol. Apr;14(4),pp. 379-83.

Nandapalan V, Jones TM, Morar P, Clark AH \& Jones AS (1998). Localized amyloidosis of the parotid gland: a case report and review of the localized amyloidosis of the head and neck. Head Neck. Jan;20(1), pp. 73-8.

Neben-Wittich MA, Foote RL \& Kalra S (2007). External beam radiation therapy for tracheobronchial amyloidosis. Chest. Jul;132(1),pp. 262-7.

Neuner GA, Badros AA, Meyer TK, Nanaji NM \& Regine WF (2010). Complete resolution of laryngeal amyloidosis with radiation treatment. Head Neck. Nov 10. [Epub ahead of print]

Nguyen TU, Oghalai JS, McGregor DK, Janssen NM \& Huston D (2001). Subcutaneous nodular amyloidosis: a case report and review of the literature. Hum Pathol. Mar;32(3):346-8.

O'Halloran LR \& Lusk RP (1994). Amyloidosis of the larynx in a child. Ann Otol Rhinol Laryngol;108,pp. 339-40.

Özdemir İ, Öztürkcan S, Güvenç IA, Özkul Y, Başoğlu S \& Etit D (2010). Localized Amyloidosis in the Nasopharynx and Neck: Case Report Turkiye Klinikleri J Med Sci; 30(1),pp. 421-4

Paccalin M, Hachulla E, Cazalet C, Tricot L, Carreiro M, Rubi M, Grateau G \& Roblot P (2005). Localized amyloidosis: a survey of 35 French cases. Amyloid. Dec;12(4), pp. 239-45.

Panda NK, Saravanan K, Purushotaman GP, Gurunathan RK \& Mahesha V (2007). Localized amyloidosis masquerading as nasopharyngeal tumor: a review. Am J Otolaryngol. May-Jun;28(3),pp. 208-11. 
Pang KP, Chee LW \& Busmanis I (2001). Amyloidoma of the nose in a pediatric patient: a case report Am J Otolaryngol. Mar-Apr;22(2),pp. 138-41.

Passerotti GH, Caniello M, Hachiya A, Santoro PP, Imamura R \& Tsuji DH (2008). Multiplesited amyloidosis in the upper aerodigestive tract: case report and literature review. Braz J Otorhinolaryngol. May-Jun;74(3):462-6.

Patel A, Pambuccian S \& Maisel R (2002). Nasopharyngeal amyloidosis. Am J Otolaryngol. Sep-Oct;23(5),pp. 308-11.

Penner CR \& Muller S (2006). Head and neck amyloidosis: a clinicopathologic study of 15 cases. Oral Oncol. Apr;42(4),pp. 421-9. Epub 2006 Feb 20.

Pentenero M, Davico Bonino L, Tomasini C, Conrotto D \& Gandolfo S (2006). Localized oral amyloidosis of the palate. Amyloid. Mar;13(1)pp., 42-6.

Piazza C, Cavaliere S, Foccoli P, Toninelli C, Bolzoni A \& Peretti G (2003). Endoscopic management of laryngo-tracheobronchial amyloidosis: a series of 32 patients. Eur Arch Otorhinolaryngol. Aug;260(7),pp. 349-54. Epub 2003 Feb 26.

Prasad D, Somayaji GK, Aroor R \& Abdulla MN (2009). Primary nasal amyloidosis. The Internet Journal of Otorhinolaryngology. Volume 9 Number 2

Simpson GT 2nd, Strong MS, Skinner M \& Cohen AS (1984). Localized amyloidosis of the head and neck and upper

aerodigestive and lower respiratory tracts. Ann Otol Rhinol Laryngol. Jul-Aug;93(4 Pt 1),pp. 374-9.

Sipe JD \& Cohen AS (1998). Amyloidosis, In: Harrison's Principles of International Medicine, Fauci AS, Braunwald E, Isselbacher KJ, Wilson JD,Martin JB, Kasper DL, Hauser SL, Longo DL pp.1856-60, McGraw-Hill Companies, Inc., ISBN 0-07-115272-5, USA.

Shimauchi T, Shin JH \& Tokura Y (2006). Primary cutaneous amyloidosis of the auricular concha: case report and review of published work. J Dermatol. Feb;33(2),pp. 128-31.

Stimson PG, Tortoledo ME, Luna MA \& Ordõnez NG (1988). Localized primary amyloid tumor of the parotid gland. Oral Surg Oral Med Oral Pathol. Oct;66(4), pp. 466-9.

Teo DT, Lau DP \& Sethi DS (2003). Recurrent localized sinonasal amyloidosis: A case report. Otolaryngology- Head and Neck Surgery. Aug; 129, pp. 270.

Tsikoudas A, Martin-Hirsch DP \& Woodhead CJ (2001). Primary sinonasal amyloidosis. J Laryngol Otol. Jan;115(1),pp. 55-6.

Tsuji T, Yamasaki H, Sasho H, Arima N \& Tsuda H (2008). Localized amyloidosis in the tonsil. Rinsho Ketsueki. Dec;49(12):1628-30.

Xu L, Cai BQ, Zhong X \& Zhu YJ (2005). Respiratory manifestations in amyloidosis. Chin Med J (Engl). Dec 20;118(24),pp. 2027-33.

Yamaoka Y, Sukuki H, Hatakeyama S, Noda M, Hiraga M \& Sekiyama S, (1978). Median rhomboid glossitis associated with amyloid deposition. Acta Pathologica Japonica 28,pp.319-323.

Yamazaki K, Sato H, Ishijima K, Abe T \& Ishikawa K (2011). A case of hemodialysisassociated amyloidosis localized to the external auditory canal. Auris Nasus Larynx. Apr;38(2),pp. 295-9. Epub 2010 Oct 28.

Yiotakis I, Georgolios A, Charalabopoulos A, Hatzipantelis P, Golias C, Charalabopoulos K \& Manolopoulos L (2009). Primary localized laryngeal amyloidosis presenting with hoarseness and dysphagia: a case report. J Med Case Reports. Sep 16;3,pp. 9049.

Zhuang YL, Tsai TL \& Lin CZ (2005). Localized amyloid deposition in the nasopharynx and neck, mimicking nasopharyngeal carcinoma with neck metastasis. Chin Med Assoc. Mar;68(3),pp. 142-5. 


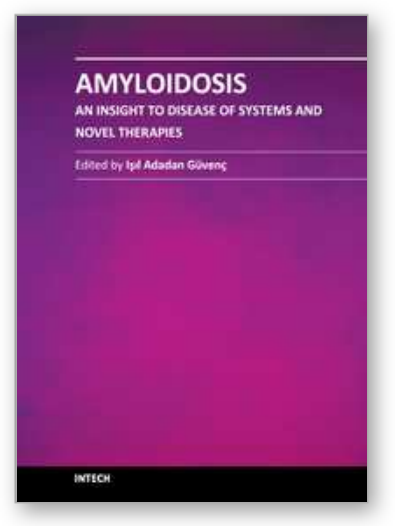

\author{
Amyloidosis - An Insight to Disease of Systems and Novel \\ Therapies \\ Edited by Dr. Işıl Adadan Güvenç
}

ISBN 978-953-307-795-6

Hard cover, 194 pages

Publisher InTech

Published online 16, November, 2011

Published in print edition November, 2011

Amyloidosis is a benign, slowly progressive condition characterized by the presence of extracellular fibrillar proteins in various organs and tissues. It has systemic or localized forms. Both systemic and localized amyloidosis have been a point of interest for many researchers and there have been a growing number of case reports in the literature for the last decade. The aim of this book is to help the reader become familiar with the presentation, diagnosis and treatment modalities of systemic and localized amyloidosis of specific organs or systems and also cover the latest advancements in therapy.

\title{
How to reference
}

In order to correctly reference this scholarly work, feel free to copy and paste the following:

Işil Adadan Güvenç (2011). Localized Amyloidosis of the Head and Neck, Amyloidosis - An Insight to Disease of Systems and Novel Therapies, Dr. Işıl Adadan Güvenç (Ed.), ISBN: 978-953-307-795-6, InTech, Available from: http://www.intechopen.com/books/amyloidosis-an-insight-to-disease-of-systems-and-noveltherapies/localized-amyloidosis-of-the-head-and-neck

\section{INTECH}

open science | open minds

\section{InTech Europe}

University Campus STeP Ri

Slavka Krautzeka 83/A

51000 Rijeka, Croatia

Phone: +385 (51) 770447

Fax: +385 (51) 686166

www.intechopen.com

\section{InTech China}

Unit 405, Office Block, Hotel Equatorial Shanghai

No.65, Yan An Road (West), Shanghai, 200040, China

中国上海市延安西路65号上海国际贵都大饭店办公楼 405 单元

Phone: +86-21-62489820

Fax: +86-21-62489821 
(C) 2011 The Author(s). Licensee IntechOpen. This is an open access article distributed under the terms of the Creative Commons Attribution 3.0 License, which permits unrestricted use, distribution, and reproduction in any medium, provided the original work is properly cited. 